\title{
Ecologically coherent population structure of uncultivated bacterioplankton
}

\author{
Conny Sjöqvist ${ }^{1,2} \cdot$ Luis Fernando Delgado $^{1} \cdot$ Johannes Alneberg ${ }^{1} \cdot$ Anders F. Andersson $^{1}{ }^{1}$
}

Received: 4 December 2020 / Revised: 31 March 2021 / Accepted: 9 April 2021 / Published online: 5 May 2021

(c) The Author(s) 2021. This article is published with open access

\begin{abstract}
Bacterioplankton are main drivers of biogeochemical cycles and important components of aquatic food webs. While sequencing-based studies have revealed how bacterioplankton communities are structured in time and space, relatively little is known about intraspecies diversity patterns and their ecological relevance. Here, we use the newly developed software POGENOM (POpulation GENomics from Metagenomes) to investigate genomic diversity and differentiation in metagenome-assembled genomes from the Baltic Sea, and investigate their genomic variation using metagenome data spanning a $1700 \mathrm{~km}$ transect and covering seasonal variation at one station. The majority of the investigated species, representing several major bacterioplankton clades, displayed population structures correlating significantly with environmental factors such as salinity and temperature. Population differentiation was more pronounced over spatial than temporal scales. We discovered genes that have undergone adaptation to different salinity regimes, potentially responsible for the populations' existence along with the salinity range. This in turn implies the broad existence of ecotypes that may remain undetected by rRNA gene sequencing. Our findings emphasize the importance of physiological barriers, and highlight the role of adaptive divergence as a structuring mechanism of bacterioplankton species.
\end{abstract}

\section{Introduction}

Each liter of seawater contains around a billion bacterial and archaeal cells (bacterioplankton) that play central roles in biogeochemical cycles, marine food webs and ecosystem services $[1,2]$. The diversity of aquatic prokaryotes is immense [3]. How this diversity is generated and structured is far from fully understood. Aquatic taxa are differentially distributed among habitats [4] and ribosomal RNA (rRNA) gene sequencing has shown that bacterioplankton communities are structured both in time and space [5-8]. While

Supplementary information The online version contains supplementary material available at https://doi.org/10.1038/s41396021-00985-z.

Anders F. Andersson

anders.andersson@scilifelab.se

1 KTH Royal Institute of Technology, Science for Life Laboratory, Department of Gene Technology, School of Engineering Sciences in Chemistry, Biotechnology and Health, Stockholm, Sweden

2 Åbo Akademi University, Faculty of Science and Engineering, Environmental and Marine Biology, Åbo, Finland these studies have demonstrated that 16S rRNA gene clusters (OTUs), or even specific 16S rRNA gene sequences (amplicon sequence variants; ASVs), represent lineages adapted to different habitats, the 16S rRNA gene does generally not provide sufficient genetic resolution to reveal within-species (intraspecific) diversity patterns, since prokaryotes with identical 16S rRNA gene sequences may have highly divergent genomes and phenotypes [9].

Comparative genomics of isolates, as well as metagenomics on natural samples, have revealed sequence clusters of $>95 \%$ average nucleotide identity (which has emerged as an operational delineation of prokaryotic species [10]); however, it is not known to what extent this intraspecific genomic variation represents neutral diversity vs. adaptation to different niches. Due to the technical challenges, relatively little is known about intraspecific structuring of microbes, not least in the marine environment. However, pioneering studies have shown that genetic content of single bacterial species may correlate with geographic distance [11], and that coexisting but ecologically differentiated strains may arise through resource partitioning [12]. For example, the picocyanobacterium Prochlorococcus has been demonstrated to display fine-scale sequence clusters associated with different regimes in temperature and light- 
intensity, and single-cell sequencing has revealed distinct genomic backbones within clusters and variation in accessory genes mainly between clusters [13]. The ubiquitous and most abundant type of organism in the ocean, the SAR11 clade, has undergone adaptive radiation in response to temperature [14]. Apart from "genome streamlining" $[14,15]$, it has been postulated that the ecological success of this organism is facilitated by its adaptive divergence into ecotypes specialized for specific environmental conditions $[6,16]$. However, it is not known if intraspecific nichedifferentiation is a general phenomenon in bacterioplankton or a characteristic of exceptionally abundant species. A deeper understanding of intraspecific diversity, sometimes referred to as "microdiversity" [17], is of crucial importance if we want to understand the ecology, evolution, and speciation of bacterioplankton, and of prokaryotes in general. Studying genomic variation within a species can also reveal genes involved in adaptation to specific environmental factors, providing new clues on gene functions and cellular mechanisms of adaptation.

The study of metagenomes has been predicted to offer a more realistic view of prokaryotic diversity $[18,19]$ as compared to PCR-based surveys of the $16 \mathrm{~S}$ rRNA gene. Metagenomics offers different routes for addressing intraspecific variation. The first is to reconstruct genetic information of individual strains. By mapping reads from one or several samples to the reference genome(s) of a species, the gene complement and/or nucleotide sequences at variant positions of the constituent strains can be inferred [20-22]. This approach is promising, but challenging, especially in cases of many coexisting strains. The second approach does not aim at reconstructing strains, but rather uses the reads mapped to a reference genome to quantify intra- and intersample genomic variation of the species. This approach is more straightforward for analyzing population structure and works well also in case of highly complex pangenomes. Schloissnig et al. [23] conducted pioneering cross-continental comparative analyses of human gut microbiomes using this approach and showed that there is more intraspecific genetic differentiation between habitats (human individuals) than within the same habitat over time. Similar approaches have been used by Nayfach et al. [11] and Delmont et al. [24] to show that gene content and amino acid composition, respectively, differ between oceanic regions within individual bacterial species.

Here we present the software POGENOM (POpulation GENOmics from Metagenomes) that, similarly to MIDAS [11], metaSNV [25] and inStrain [26] quantifies intraspecific genomic variation from metagenomic data. POGENOM differs from these softwares in that it takes as input a Variant Call Format (VCF) file, the standard file format for storing gene sequence variations. This allows the user to apply a variant caller of choice, rather than relying on an inbuilt algorithm. While MIDAS and inStrain provide genome-wide and gene-specific diversity estimates, metaSNV reports genome-wide population differentiation (Manhattan distance). POGENOM outputs both diversity and differentiation parameters, at the whole genome (nucleotide diversity and fixation index $\left(F_{\mathrm{ST}}\right)$ ) and at the gene level (nucleotide and amino acid diversity, $\mathrm{pN} / \mathrm{pS}$, and $F_{\mathrm{ST}}$ based on nucleotides and amino acids). POGENOM also provides permuted gene-wise $F_{\mathrm{ST}}$ values, facilitating significance tests on gene-wise differentiation.

We here use POGENOM to investigate patterns of genomic variation among a set of bacterioplankton species in the Baltic Sea. The Baltic Sea is a geologically young ecosystem with pronounced gradients of salinity, temperature, and nutrient concentrations, and is often used as a model for postglacial colonization and ecological differentiation [27, 28]. Marine macroorganisms display reduced species richness and intraspecific diversity towards the northern Baltic Sea, as the lower salinity of these waters impose more challenging conditions. Likewise, freshwater species diversity decreases with increasing salinity levels towards the south-west [29]. Moreover, population genetic studies have shown that species of fish and macroalgae have distinct genetic populations in the Baltic Proper (central Baltic Sea) compared to the Atlantic west of Sweden [3032]. With respect to microorganisms, population genetic data across the salinity regimes is only available for one eukaryote: the marine diatom Skeletonema marinoi [33]. It is evident that the species is locally adapted and genetically differentiated into separate populations on each side of the Danish Straits, correlating with different salinity regimes and oceanographic connectivity. For bacterioplankton, community composition has been shown to vary significantly along the horizontal salinity gradient, as well as vertically along oxygen gradients, with the Baltic Proper being composed of a mixture of typical freshwater and marine taxa [34, 35]. Using metagenomic binning and fragment recruitment analysis, Hugerth et al. [36] showed that the prokaryotic organisms in the Baltic Proper are genetically differentiated from closely related marine and freshwater lineages while displaying high similarity to sequences from North American brackish waters, suggesting that the Baltic Sea prokaryotes are members of a global meta-community adapted to brackish conditions. However, it remains to be investigated whether the bacterioplankton species display genetically structured populations within the Baltic Sea ecosystem.

\section{Results}

To improve understanding in intraspecific variation and revealing patterns in population genomic structure in 
Table 1 BACLs for which a representative MAG was included in the population genomic analysis and their overall SNV frequency (number of variant loci/genome size) and mean within-sample nucleotide diversity $(\pi)$. The table is ordered by taxonomy.

\begin{tabular}{|c|c|c|c|c|c|c|c|}
\hline Baltic Cluster & $\begin{array}{l}\text { Genome } \\
\text { size (bp) }\end{array}$ & $\begin{array}{r}\text { Number } \\
\text { variant loci }\end{array}$ & $\begin{array}{r}\text { SNP } \\
\text { frequency }\end{array}$ & $\begin{array}{l}\text { Mean intra- } \\
\text { sample } \pi\end{array}$ & Phylum & Family & Genus \\
\hline BACL13 & 1404359 & 2954 & 0.0021 & 0.0006 & Crenarchaeota & Nitrosopumilaceae & Nitrosopumilus \\
\hline BACL27 & 1786241 & 26173 & 0.0147 & 0.0033 & Actinobacteriota & Ilumatobacteraceae & BACL27 \\
\hline BACL17 & 1756084 & 22436 & 0.0128 & 0.0026 & Actinobacteriota & Ilumatobacteraceae & UBA3006 \\
\hline BACL6 & 2791422 & 12221 & 0.0044 & 0.0011 & Actinobacteriota & Ilumatobacteraceae & UBA3006 \\
\hline BACL112 & 1305743 & 13388 & 0.0103 & 0.0029 & Actinobacteriota & AcAMD-5 & ATZT02 \\
\hline BACL2 & 1227951 & 23983 & 0.0195 & 0.004 & Actinobacteriota & Nanopelagicaceae & MAG-120802 \\
\hline BACL15 & 1276454 & 8011 & 0.0063 & 0.0015 & Actinobacteriota & Nanopelagicaceae & Planktophila \\
\hline BACL18 & 1767133 & 14674 & 0.0083 & 0.0016 & Bacteroidota & Cryomorphaceae & TMED14 \\
\hline BACL8 & 2159345 & 6697 & 0.0031 & 0.0008 & Bacteroidota & Flavobacteriaceae & MAG-120531 \\
\hline BACL327 & 1850878 & 26602 & 0.0144 & 0.0034 & Cyanobacteria & Cyanobiaceae & PCC7001 \\
\hline BACL325 & 838244 & 15671 & 0.0187 & 0.0038 & Proteobacteria & Pelagibacteraceae & NA \\
\hline BACL144 & 1246612 & 17204 & 0.0138 & 0.003 & Proteobacteria & Pelagibacteraceae & NA \\
\hline BACL149 & 1310694 & 13757 & 0.0105 & 0.0026 & Proteobacteria & Pelagibacteraceae & IMCC9063 \\
\hline BACL53 & 1312850 & 23119 & 0.0176 & 0.0032 & Proteobacteria & Pelagibacteraceae & IMCC9063 \\
\hline BACL5 & 1242356 & 8386 & 0.0068 & 0.0016 & Proteobacteria & Pelagibacteraceae & Pelagibacter \\
\hline BACL262 & 1130444 & 12534 & 0.0111 & 0.0026 & Proteobacteria & Pelagibacteraceae & Pelagibacter \\
\hline BACL214 & 2228508 & 25432 & 0.0114 & 0.0024 & Proteobacteria & Burkholderiaceae & UBA2463 \\
\hline BACL14 & 1388129 & 7055 & 0.0051 & 0.0013 & Proteobacteria & Methylophilaceae & BACL14 \\
\hline BACL3 & 2958067 & 16697 & 0.0056 & 0.0013 & Proteobacteria & Pseudohongiellaceae & OM182 \\
\hline BACL1 & 1513717 & 15731 & 0.0104 & 0.0018 & Proteobacteria & D2472 & D2472 \\
\hline BACL168 & 2226010 & 4876 & 0.0022 & 0.0005 & Verrucomicrobiota & NA & NA \\
\hline BACL9 & 1774586 & 12495 & 0.007 & 0.0018 & Verrucomicrobiota & UBA3015 & UBA3015 \\
\hline
\end{tabular}

bacterioplankton, we applied our newly developed software POGENOM on a set of MAGs that was recently reconstructed from a dataset of 123 water samples covering environmental gradients of the Baltic Sea [37] (Supplementary Table 1). This set includes 1961 MAGs that were clustered at $96.5 \%$ average nucleotide identity (ANI) into 352 species-level clusters [35]. These clusters are hereafter referred to as BACLs (BAltic Sea CLusters), and sometimes, for convenience, the term species is used, although these are not strict species. We selected a subset of 22 BACLs for our analyses, displaying sufficiently high coverage in at least ten surface water samples (see Methods). For each BACL, one representative MAG was used (with average estimated completeness and contamination of $91 \%$ and 3\%, respectively; Table 1 and Supplementary Table 2). Metagenome reads from surface water samples from two transect cruises (Pelagic Transect $2014(n=10)$ and Coastal Transect $2015(n=34))$ and from a 2-year time-series from one off-shore station (the Linnaeus Microbial Observatory $(n=22)$ ) (Fig. 1 and Supplementary Table 1) were mapped to the MAGs $[37,38]$. To lower the risk of including reads derived from other species, we only included reads mapping with $>95 \%$ identity to the MAGs. We further used a median coverage depth threshold of $\geq 20 \mathrm{X}$ and a minimum coverage breadth of $40 \%$ to include a sample for a BACL. To avoid biases stemming from differences in coverage depth between samples, mapped reads were downsampled to the same median coverage (20X) for all samples.

\section{Nucleotide diversity}

In total, 355,951 single-nucleotide polymorphisms were identified in the 22 genomes, with frequencies ranging from $0.0021 \mathrm{kbp}^{-1}$ (BACL13) to $0.0195 \mathrm{~kb}^{-1}$ (BACL2). Mean within-sample nucleotide diversity $(\pi)$, corresponding to the likelihood that two metagenome reads that overlap a position in the genome will differ at the position, ranging from 0.0005 (BACL168) to 0.0040 (BACL2) (Table 1). Since intraspecific genetic diversity tends to decline towards the extremes of a species' niche-gradients [39], we investigated if any patterns in $\pi$ across the salinity gradient could be detected. Indeed, eight out of the 22 genomes displayed a significant non-linear pattern (quadratic regression model) of within-sample $\pi$, while the $\pi$ of two genomes (BACL1 and BACL5) best fit a linear regression model with salinity (Fig. 2, Supplementary Table 3). The observed non-uniform patterns of $\pi$ are likely not caused by biases between the 
Fig. 1 The Baltic Sea salinity gradient. Based on daily average surface salinity data from 2007 to 2017. Data retrieved from the Baltic Marine Environment Protection Commission (http://metadata. helcom.fi/). Sampling sites for the metagenomic data sets used in this study are indicated with symbols.

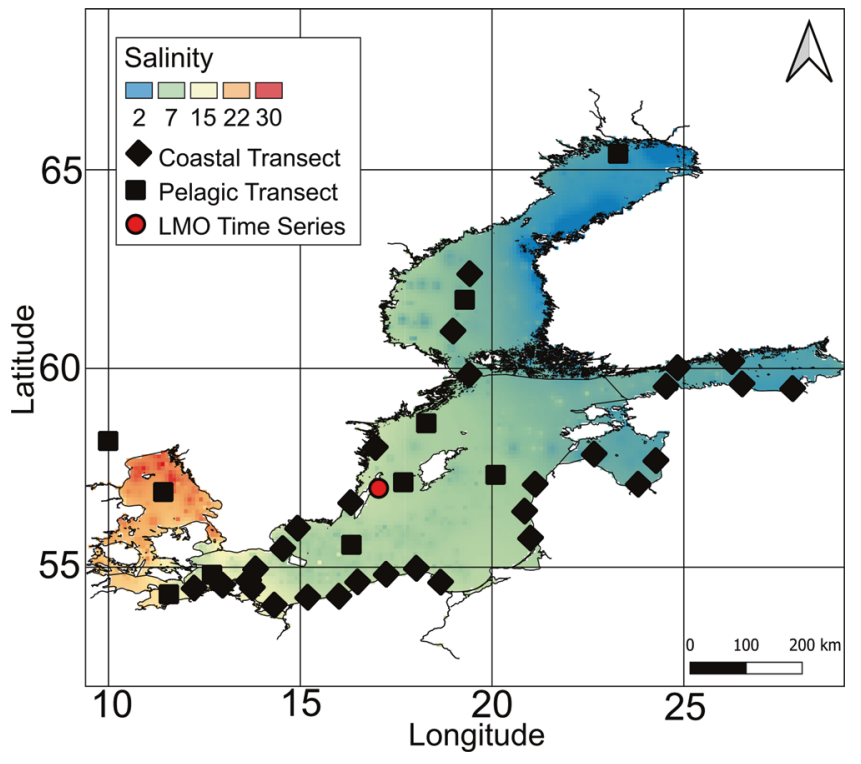

sequencing depth would reveal even clearer population structures, due to reduced noise in the $F_{\mathrm{ST}}$ computations. However, benchmarking on one genome showed that $F_{\text {ST }}$ values calculated using the applied coverage correlated well (Pearson $R=0.88$ ) with values obtained using four times higher coverage (Supplementary Fig. 2).

Of the four genomes that were present in at least eight of the LMO time-series samples, two (BACL1 and BACL149) displayed a significant correlation between $F_{\mathrm{ST}}$ and temperature $(p<0.001$; data not shown). We did not observe any significant correlations between population structure and season, when accounting for the correlation with temperature.

Among the BACLs for which a comparison between genomic differentiation over time and space was feasible, the magnitude of differentiation was greater spatially across the Baltic Sea than temporally at station LMO in six out of eight cases (Fig. 5). For four of them, the difference was statistically significant.

\section{Genetic variation at the gene level}

The previous analyses reveal patterns of genomic variation at the whole genome level. To investigate patterns of selective constraints in these genomes, POGENOM estimates the ratio of non-synonymous to synonymous polymorphism rates $(\mathrm{pN} / \mathrm{pS})$ for each gene and sample, where low values indicate negative (purifying) selection and high values relaxed negative selection or diversifying selection. As expected, house-keeping genes (using a set of 36 single-copy core genes (SCGs) that are found in single-copy in nearly all known bacterial genomes [40]) had on average lower $\mathrm{pN} / \mathrm{pS}$ values than other genes in most (20/22) genomes (Supplementary Fig. 2), reflecting also for these. Similarly, it is possible that a higher 
D2472, BACL1

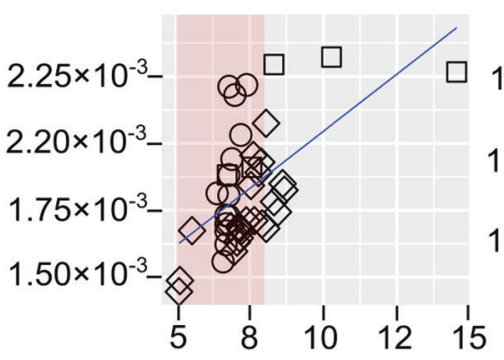

Illumatobacteraceae, BACL6

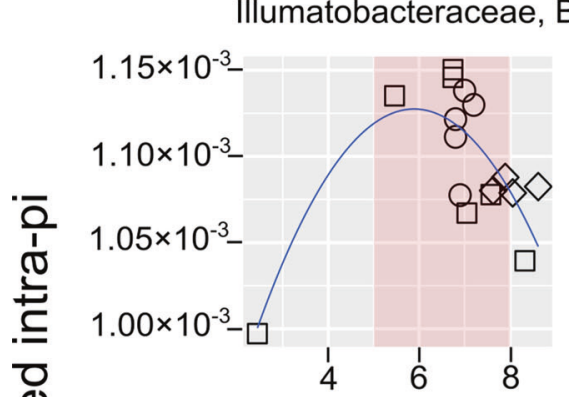

$1.90 \times 10^{-3}$

UBA3015, BACL9

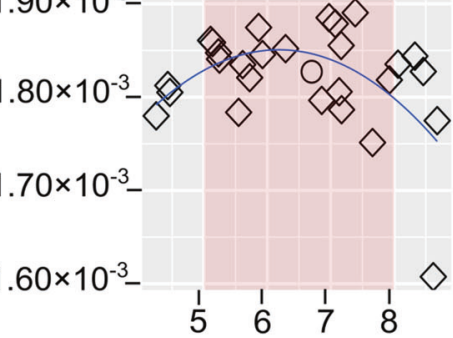

Illumatobacteraceae, BACL17 AcAMD-5, BACL112

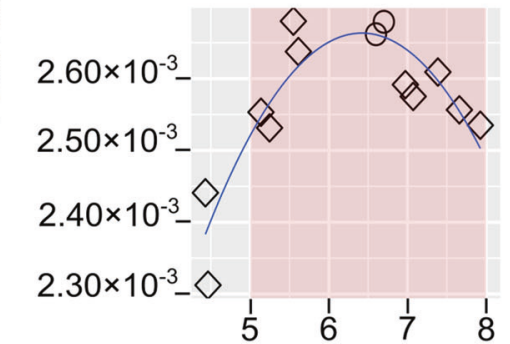

$3.00 \times 10^{-3}$

$2.90 \times 10^{-3}-8$

$2.80 \times 10^{-3}$

$2.70 \times 10^{-3}$

$2.60 \times 10^{-3}$

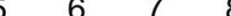
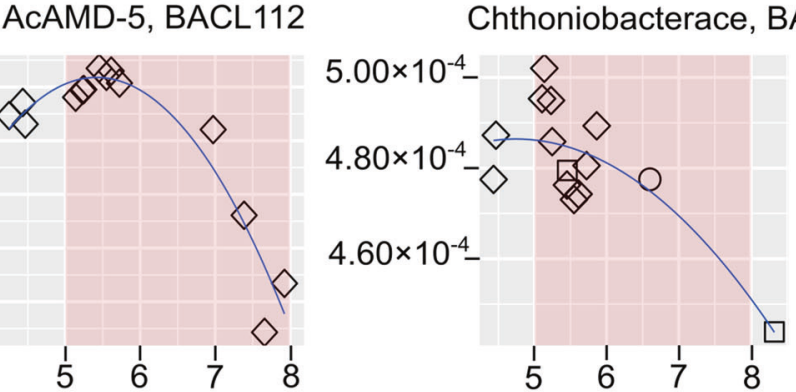

Pelagibacteraceae, BACL262

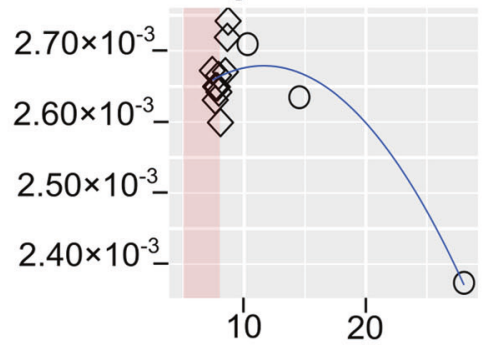

Fig. 2 Intrapopulation $\pi$ vs. salinity across the Baltic Sea ecosystem. Shaded area in red indicates salinity 5-8 (the horohalinicum [88]), to simplify the comparison of the graphs. Note different scales on $y$ - and $x$-axes. All plotted genomes (10 of the 22 genomes) show statistically significant $(p<0.05)$ correlation with salinity, either using

stronger purifying selection in genes with core functions than in average genes [41, 42]. Likewise, comparing pN/ $\mathrm{pS}$ values between genes belonging to different Kyoto Encyclopedia of genes and genomes (KEGG) [43] pathways showed that the pathways with lowest average $\mathrm{pN} /$ $\mathrm{pS}$ values (indicative of negative selection) tended to be associated with house-keeping processes such as $\diamond$ Coastal Transect

Pelagic Transect L LMO Time Series

\section{Salinity}

a linear (BACL1, BACL5) or quadratic regression model (all other BACLs), chosen based on the lowest AIC (Akaike information criterion) value. Complementary information (Supplementary Table 3) include statistical parameters for all models (also non-significant).

transcription, RNA degradation, nucleotide excision repair and oxidative phosphorylation (Fig. 6, upper panel). Among the pathways with the highest $\mathrm{pN} / \mathrm{pS}$ ratios (Fig. 6, lower panel), suggesting relaxed purifying selection or diversifying selection, we found several related to biofilm formation and antimicrobial synthesis and resistance. The pathway with the highest $\mathrm{pN} / \mathrm{pS}$ value $(0.52)$ in 


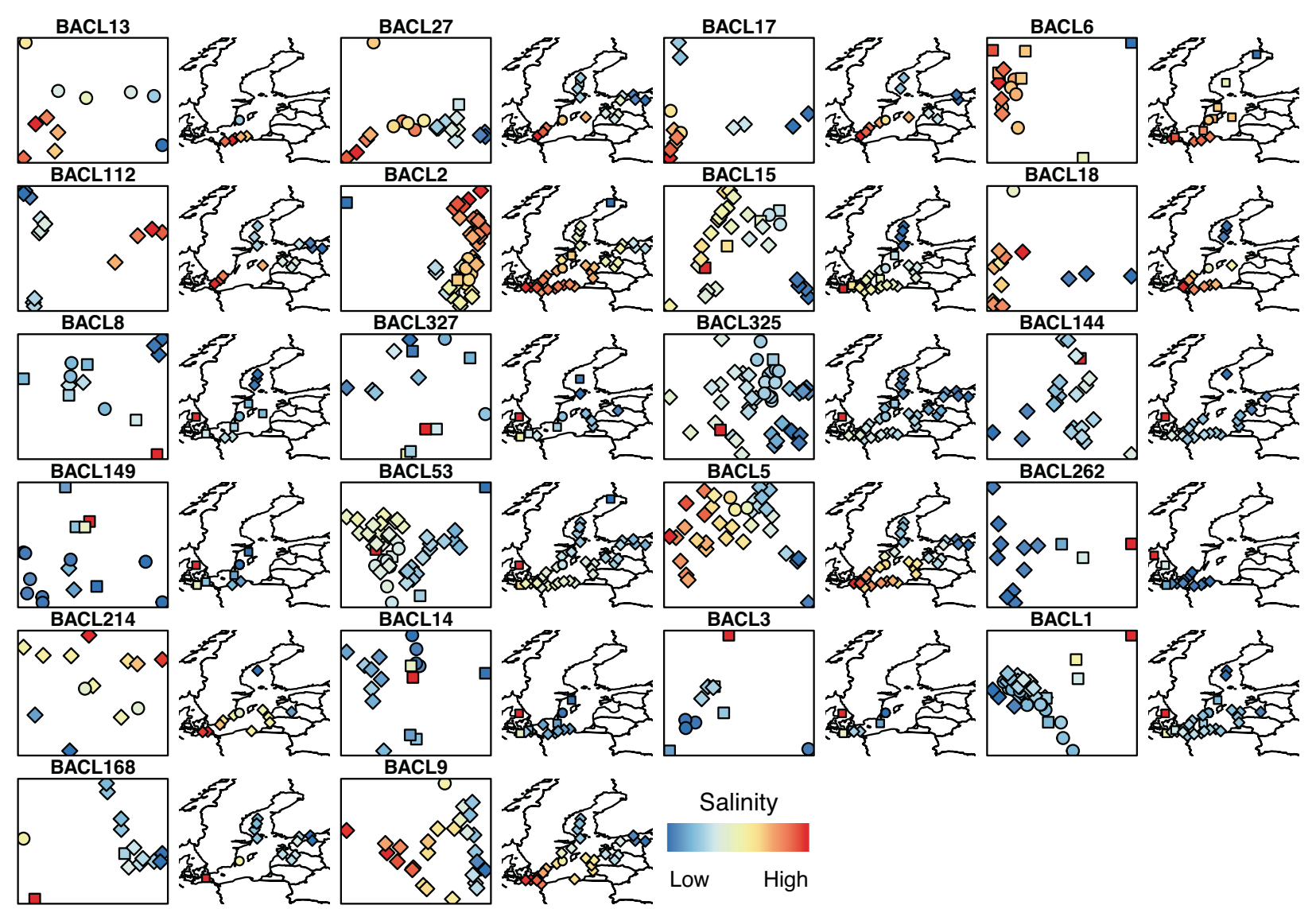

Fig. 3 Population structure of Baltic Sea bacterioplankton. Left hand panel for each BACL represents a PCoA based on $F_{\mathrm{ST}}$ values, each data point is one sample. Right hand panel depicts the geographic location for each sampling point. The symbol colors indicate salinity

values, with independent scales for the different BACLs. Circles $=$ LMO Time series, squares $=$ Pelagic Transect, diamonds $=$ Coastal Transect.

a single genome (BACL13) was cationic antimicrobial peptide (CAMP) resistance.

To identify environmental selection on specific genes, we focused on salinity, since this was the major driver of population structure in most BACLs. To facilitate the interpretation of population structure, POGENOM calculates $F_{\mathrm{ST}}$ at the individual gene level. For the 19 genomes that were present in at least ten transect samples, between 65 (BACL327) and 1245 (BACL18) genes displayed a positive correlation between $F_{\mathrm{ST}}$ and difference in salinity (Spearman correlation, FDR adjusted $p<0.05$ ). These correlations may indicate that the genes themselves have undergone adaptation to the different salinity levels (or to environmental factors that co-vary with salinity) but could also reflect genetic hitchhiking, i.e., that an allele that differs in frequency between environmental conditions does so because allele(s) elsewhere on the genome have undergone selective sweeps. To increase the chance of identifying genes that truly have undergone positive selection in relation to salinity, we investigated gene-wise $F_{\mathrm{ST}}$ values for the pair of samples with the largest difference in salinity for each genome. We devised a permutation procedure, where a permuted $F_{\mathrm{ST}}$ value is calculated for each gene by shuffling variant loci over the genome while keeping the population differentiation constant at the genome-level (see Methods). This showed that a number of genes (1-32) in all but two BACLs displayed a higher $F_{\mathrm{ST}}$ (FDR adjusted $p<0.05$ ) than expected by chance, given the genomes' background levels of differentiation (Fig. 7 gives one example). The majority $(91 \%)$ of these genes also displayed a positive correlation between $F_{\mathrm{ST}}$ and difference in salinity based on all transect samples. Pathway enrichment analysis indicated that the 151 genes that both displayed a significant $F_{\mathrm{ST}}$ for the salinity extremes and a correlation between $F_{\mathrm{ST}}$ and salinity difference were enriched in certain KEGG pathways: six pathways were enriched in at least two different BACLs each, and these were also enriched when considering all BACLs $(p<0.05$; Table 2 and Supplementary Table 4). Four of these; Nitrogen metabolism (map00910), Alanine, aspartate and glutamate metabolism (map00250), ABC transporters (map02010) and Glyoxylate and dicarboxylate metabolism (map00630) were all enriched in two actinobacterial 
Fig. 4 Environmental drivers of population structure in $\mathbf{1 9}$ prokaryotic BACLs across the pelagic and coastal transects.

The number of samples $(n)$ included for each BACL are indicated by the left-most column. Results stem from conditioned redundancy analyses. The PCNM variables represent the spatial relationship between sampling sites, reflecting pairwise geographic distances (shortest waterway distance). $R^{2}$ values are colored from blue to red; only significant correlations are shown $(p<0.05)$.
Drivers of population structure in pelagic and coastal areas
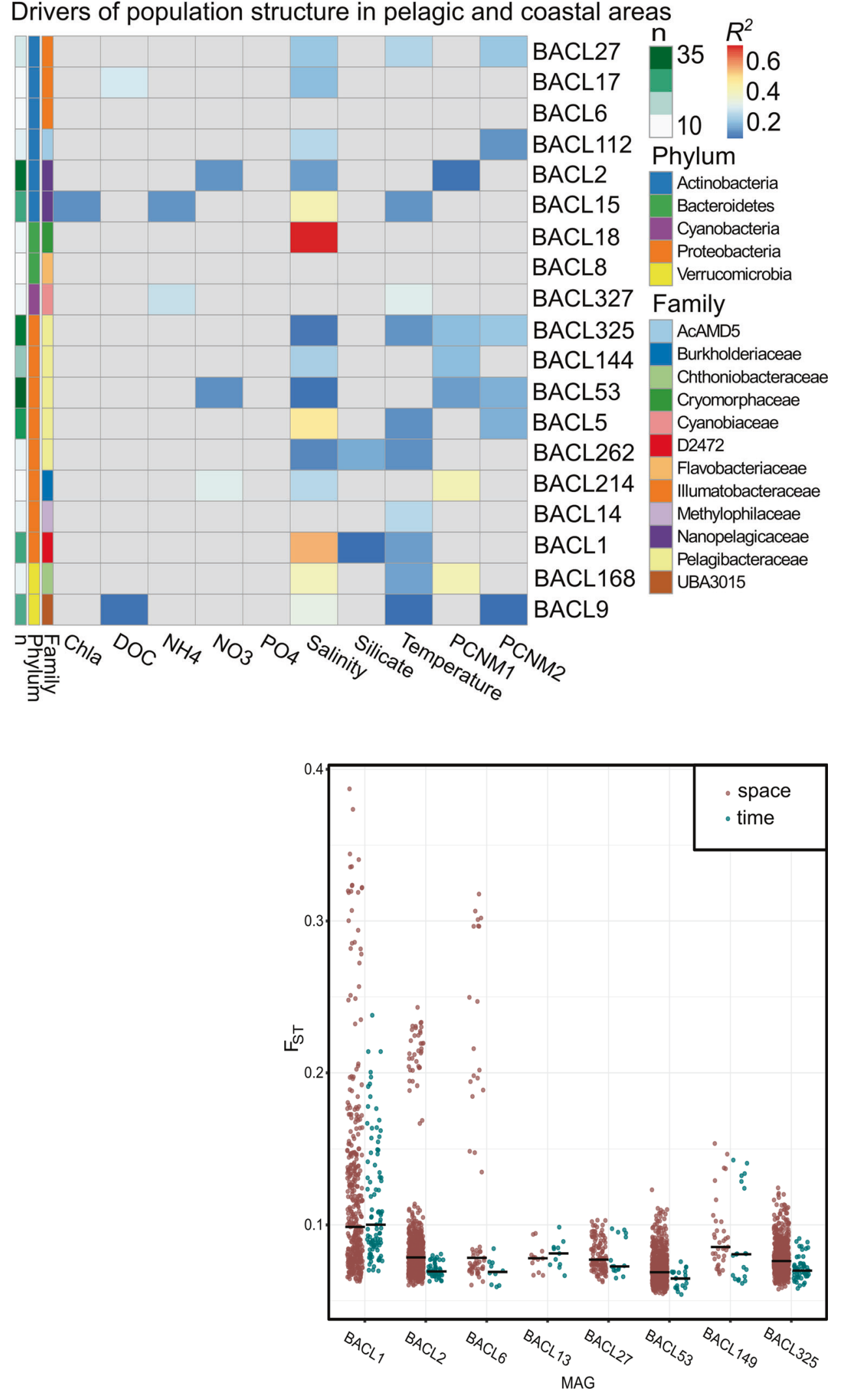

Fig. 5 Comparison of $\boldsymbol{F}_{\mathrm{ST}}$ values spatially across the Baltic Sea vs. over time at station LMO. Median values denoted with black lines. $p$ values from Wilcoxon ranksum tests comparing the distributions of $F_{\text {ST }}$ values over time and space indicated by asterisks $(<0.01 * *,<0.001 * * *)$. 


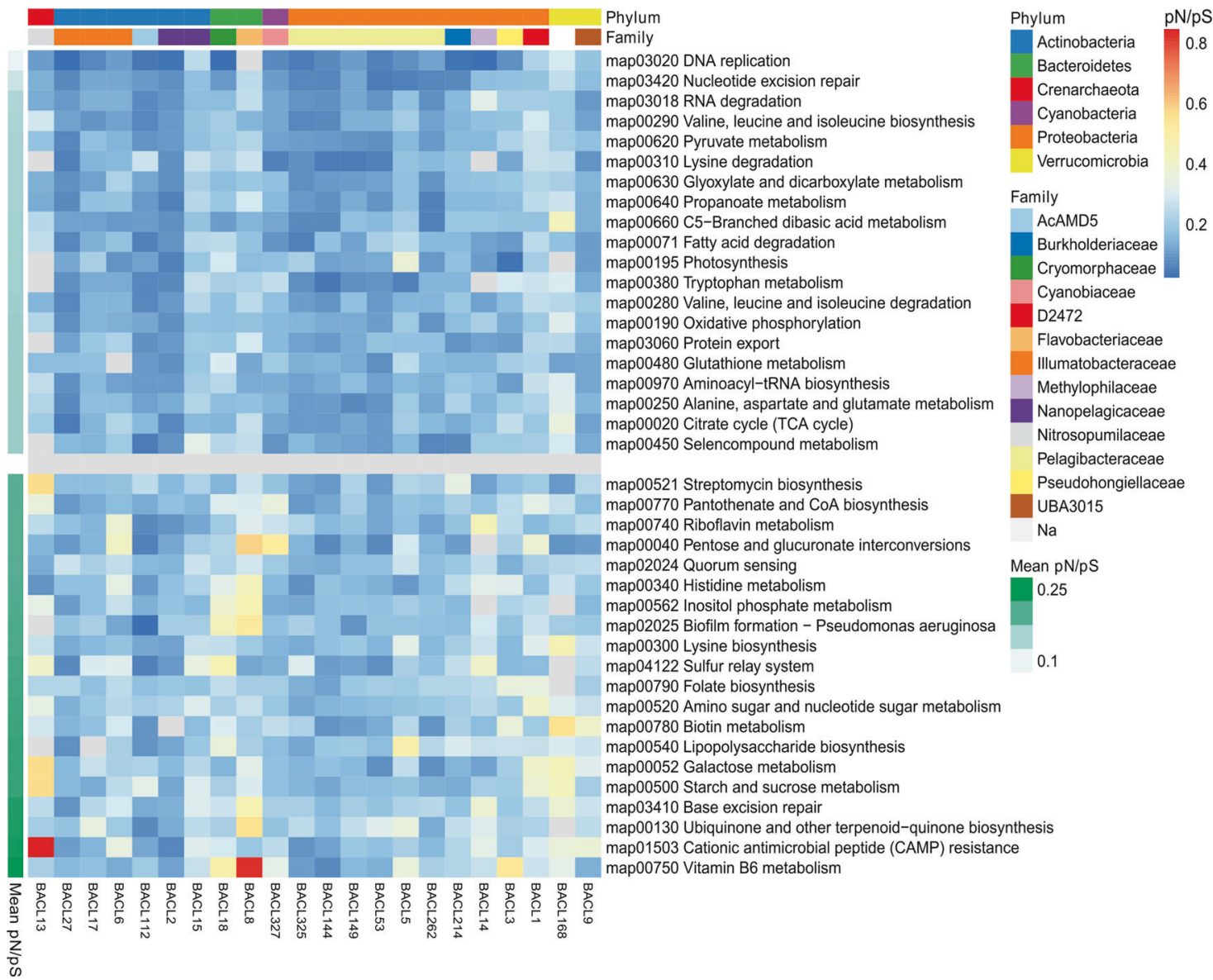

Fig. 6 Summary of pN/pS values for KEGG pathways in 22 bacterioplankton genomes. Pathways sorted by mean pN/pS across genomes. The upper and lower panel consist of the twenty KEGG pathways with the lowest and highest mean pN/pS values, respectively.

genomes each. The eggNOG category that was enriched in most genomes $(n=4)$ was Inorganic ion transport and metabolism (P).

\section{Discussion}

In this study we estimated genomic diversity and population differentiation for a set of uncultured aquatic prokaryotic species along environmental gradients across the Baltic Sea. We quantified population genomic indices, such as the intra-population diversity $(\pi)$ and the fixation index $\left(F_{\mathrm{ST}}\right)$, and quantified $\mathrm{pN} / \mathrm{pS}$ ratios for genes belonging to different pathways across the study system to detect potential biases in selection pressures. With these analyses, we obtained information about environmental drivers of population structure and indications on functional traits under selection. Such an exercise is now significantly streamlined with the software POGENOM, calculating the above parameters automatically. With intra-population diversity $(\pi)$, we refer to the average nucleotide diversity of a population, while the fixation index $\left(F_{\mathrm{ST}}\right)$, measures the differences in allele frequencies between pairwise populations. $F_{\mathrm{ST}}$ was originally designed for diploid, sexually reproducing organisms [44] where a value close to 1 is interpreted as substantially restricted gene flow between populations. However, the concept of $F_{\mathrm{ST}}$ involves no obligate condition of sexual reproduction, as it simply compares allele frequencies between two populations and is thus as valid for asexually reproducing prokaryotes [45]. Constraints in gene flow as apprehended in sexually reproducing organisms may for prokaryotes be seen as constraints in homologous recombination and/or effects of environmental sorting of genetic material, leading to skewed allele frequencies between populations.

Our analyses showed that the majority of the BACLs had a genomic population structure significantly correlating with salinity across the Baltic Sea, i.e., that the diverse and environmentally structured bacterioplankton communities that have been described earlier in this ecosystem [34, 46-48] are even further differentiated at the species level. A few BACLs displayed statistically significant isolation by distance (IBD), similar to the findings in Nayfach et al. [11]. However, variation partitioning indicated that geographic distance was the 

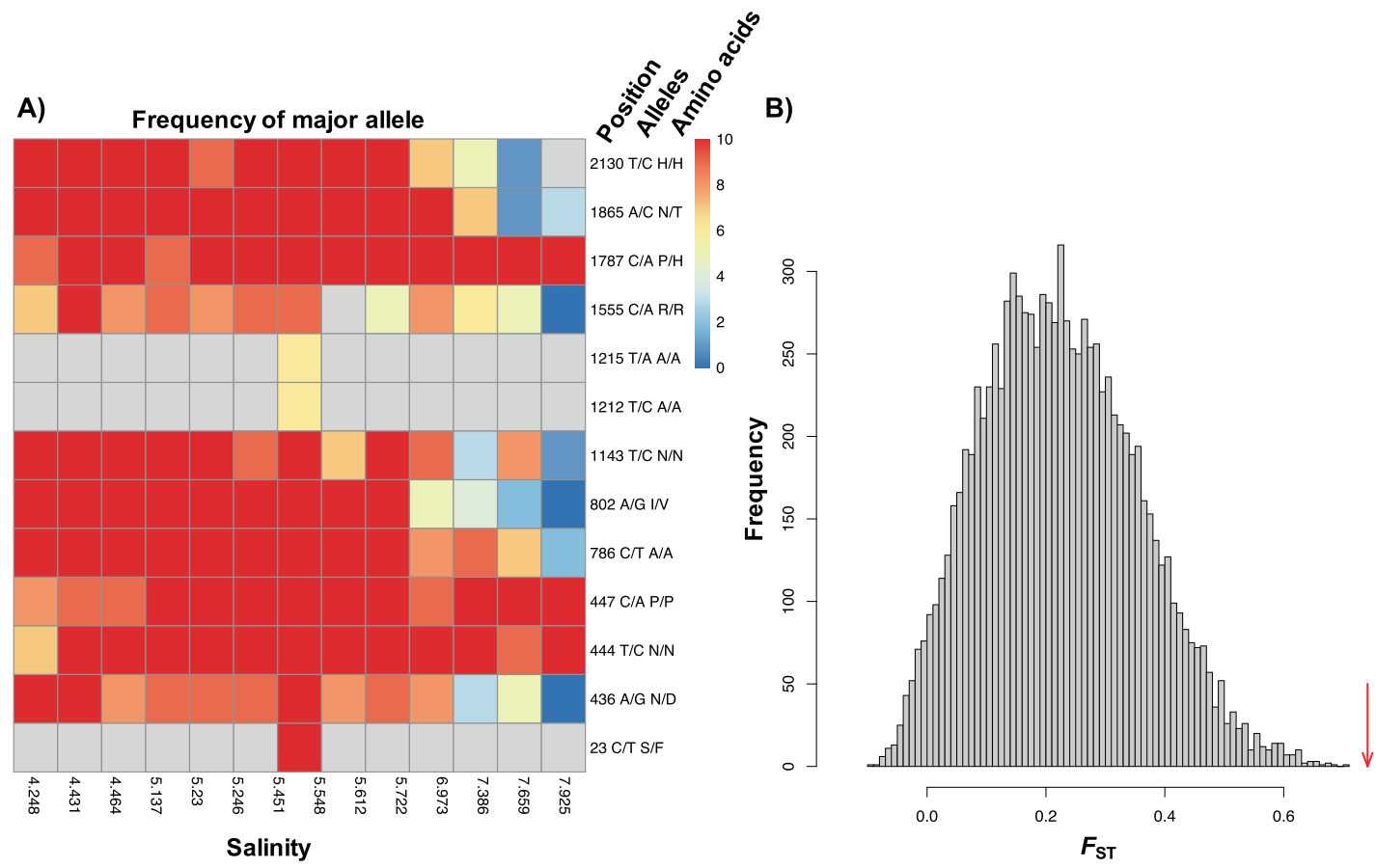

Fig. 7 Example of genetic differentiation in a gene: $\mathrm{ID}=302 \_3$ of BACL262 (ABC-type proline glycine betaine transport system permease component). A Heatmap showing allele frequencies at different salinities along the transect, the color indicates the counts of the major allele in each sample (maximum $=10$ since the counts were

strongest driver of population structure only in four cases out of 19 after taking environmental factors into account (Fig. 4). In cases where stable differential selection is sustained, as in the Baltic Sea, and where geographic distances are rather small, isolation by adaptation (IBA) can spur population structure within a species [49, 50]. When comparing the extent of differentiation across space and time, $F_{\mathrm{ST}}$ values were on average higher for geographically than temporally separated populations, which probably reflects that salinity is a stronger driver of population structure than the environmental factors that covary with season. Hence, our data indicate that intraspecific genomic differentiation is more pronounced over the spatial than the temporal scale in the Baltic Sea ecosystem, analogous to what has previously been proposed for species sorting at the community level [35]. However, a couple of BACLs displayed temporal population structures significantly covarying with temperature, exemplifying that population structure in marine bacterioplankton also adhere to variations in niches at the same geographic location. Combined, these results show that aquatic bacterial species typically diverge from the null hypothesis of panmixia and that populations are structured by species-specific environmental drivers. This in turn implies the broad existence of ecotypes [51] that may remain undetected by $16 \mathrm{~S}$ rRNA gene sequencing.

Earlier comparative genomic studies have shown remarkable differences in gene content of bacterioplankton

downsampled to this level, see Methods). Nucleotide position in the gene, major/minor alleles (nucleotides), and the resulting amino acid translations, are given to the right. B Distribution of permuted $F_{\text {ST }}$ values for the gene based on 10,000 permutations. The red arrow indicates the actual $F_{\mathrm{ST}}$ value $(0.74)$.

belonging to the same species and concluded that the flexible part of the genome is modified by horizontal gene transfer in response to selective forces [11, 52-55]. Our results suggest that environmental selection in bacterioplankton also selects for and preserves specific alleles in the existing genes. Delmont et al. [24] suggested an evolutionary mechanism for such conservation of genetic heterogeneity by emphasizing the role of adaptive selection, exemplified by the cosmopolitan SAR11 clade. The same authors showed a partitioning of SAR11 populations in concordance with large-scale oceanic temperatures, suggesting that environmental selection is of central importance even at the microdiversity level in marine bacterioplankton. Our study shows that environmentally driven population structure is not limited to species of certain clades, but rather appears to be a general pattern for bacterioplankton. We, also, observe this in several species of SAR11 (Pelagibacteraceae), but also in several other taxa. For example, BACL1, belonging to the cosmopolitan Gammaproteobacterial clade SAR86, displayed a population genomic structure mainly driven by salinity in the Baltic Sea ecosystem. Another abundant group in the Baltic Sea, the Actinobacteria, are also mostly driven by salinity according to our analyses. Actinobacteria are one of the most abundant types of freshwater bacteria globally and comprise multiple different clades and species-level clusters [56, 57]. Recent discoveries on their marked microdiversification may 
Table 2 Summary of the KEGG pathway and eggNOG category enrichment analyses on the set of genes that displayed significant $F_{\mathrm{ST}}$ levels between the BACLs' salinity extremes and significant correlations between $F_{\mathrm{ST}}$ and salinity difference.

\begin{tabular}{|c|c|c|c|c|}
\hline BACL & Family & $\begin{array}{l}\text { Number of } \\
\text { significant genes }\end{array}$ & Significant KEGG pathways & $\begin{array}{l}\text { Significant eggNOG } \\
\text { categories }\end{array}$ \\
\hline BACL27 & Ilumatobacteraceae & 2 & map00910 & $\mathrm{P}$ \\
\hline BACL17 & Ilumatobacteraceae & 13 & map00250,map02010,map00460 & E,P \\
\hline BACL6 & Ilumatobacteraceae & 26 & $\begin{array}{l}\text { map00020,map00630,map02024*,map00405, } \\
\text { map02025 }\end{array}$ & \\
\hline BACL112 & AcAMD-5 & 32 & $\begin{array}{l}\text { map03410,map00220,map00250,map00630, } \\
\text { map00910,map00471 }\end{array}$ & \\
\hline BACL2 & Nanopelagicaceae & 18 & map00984 & $\mathrm{P}$, \\
\hline BACL15 & Nanopelagicaceae & 4 & map02010 & \\
\hline BACL18 & Cryomorphaceae & 6 & map03008 & \\
\hline BACL8 & Flavobacteriaceae & 2 & map00550,map01502 & M \\
\hline BACL327 & Cyanobiaceae & 2 & map00480,map00980,map00982,map00983 & \\
\hline BACL325 & Pelagibacteraceae & 1 & & \\
\hline BACL144 & Pelagibacteraceae & 7 & map00290,map00620,map00561,map00430 & $\mathrm{E}$ \\
\hline BACL53 & Pelagibacteraceae & 13 & $\begin{array}{l}\text { map00460,map00627,map00643,map00790, } \\
\text { map04122 }\end{array}$ & $\mathrm{G}$ \\
\hline BACL5 & Pelagibacteraceae & 1 & $\operatorname{map} 00330$ & \\
\hline BACL262 & Pelagibacteraceae & 16 & map03060,map03070,map00680,map00190* & $\mathrm{U}, \mathrm{P}^{*}, \mathrm{C}$ \\
\hline BACL214 & Burkholderiaceae & 0 & & \\
\hline BACL14 & Methylophilaceae & 0 & & \\
\hline BACL1 & D2472 & 3 & map00220 & \\
\hline BACL168 & NA & 0 & & \\
\hline BACL9 & UBA3015 & 5 & map00450 & \\
\hline All & & 151 & $\begin{array}{l}\text { map02010,map00910*,map03420,map00250, } \\
\text { map00630*,map02024,map00460,map00220 }\end{array}$ & $\mathrm{P}^{*}, \mathrm{E}$ \\
\hline
\end{tabular}

The analyses included the 19 BACLs present in at least ten samples across the transect. Shown pathways/categories had $p$ values $<0.05$ in Fisher's exact tests, and those highlighted with $*$ had FDR adjusted $p$ values $<0.05$.

explain their success in environmentally variable conditions [58]. The Baltic Sea also hosts an abundant community of different cyanobacteria species. An example is the cosmopolitan genus Synechococcus, which is prevalent in the Baltic Sea during summer or when the temperature reaches $>15^{\circ} \mathrm{C}$ [59]. The environmental association analysis showed that the population structure of the Synechococcus $s p$. analyzed here (BACL327) was mainly driven by differences in sea surface temperature across the Baltic Sea. A marked difference between the situation in the Baltic Sea and in the ocean, however, is that in the ocean, temperature appears to be the main factor structuring bacterioplankton, both at the community [60,61] and population [24] level, while in the Baltic Sea, salinity is the primary driver.

Empirical studies on marginal populations of macroorganisms living close to the species range limits show decreased genetic diversity, thus lowering their adaptive potential to rapidly changing environmental conditions $[28,62]$. This has been observed in several marine macroorganisms adapted to the brackish conditions in the Baltic Sea, where the populations residing inside the Baltic display lower intra-species diversity than their Atlantic founder populations [28]. In contrast, several of the BACLs displayed a significant hump-shaped curve in intra-population diversity $(\pi)$ along the salinity gradient. However, our previous study based on MAGs from station LMO indicated that the bacterioplankton of the Baltic Sea are members of a globally distributed brackish metacommunity, rather than locally adapted freshwater and marine taxa [36]. Thus, unlike most macroorganisms in this ecosystem, planktonic prokaryotes residing in the Baltic Sea were likely adapted to brackish conditions already when they entered the system, consistent with the hump-shaped curves in diversity. Whether most of the intraspecific variation and niche differentiation that we see within the different BACLs were gained after the populations immigrated, or was in place already before, as a set of strains with different genetic make-up and ecological niches, remains elusive.

Recently, proteome differences between some freshwater prokaryotes and their closest marine relatives were described, with a larger proportion of acidic and a lower number of alkalic amino acids in the proteome of the marine 
representative of each pair, compatible with a "salt-in" strategy earlier observed in halophilic prokaryotes [63]. This indicates that adaptations changing the chemical properties of the proteome may be important for crossing the freshwater - marine boundary [64]. However, none of the 22 BACLs displayed a significant correlation between salinity level of the sample and frequency of either acidic or alkaline amino acids in the population proteome, as deduced from the per-sample single amino acid variants (SAV) frequencies output by POGENOM (data not shown). Thus, adaptations altering the physicochemical properties of the proteome does not seem to be the major driver behind the genomic differentiation we observe within the Baltic Sea region for these populations. It may however have been important for facilitating the transition from freshwater or marine to brackish conditions in the first place.

The gene-wise $\mathrm{pN} / \mathrm{pS}$ analysis addressed patterns of constraints in selection, not directly related to the environmental gradients. While we observed relatively low $\mathrm{pN} / \mathrm{pS}$ ratios reflecting purifying selection for genes belonging to KEGG pathways related to housekeeping functions, indications of diversifying selection were observed in other parts of the functional spectrum. For instance, the cationic antimicrobial peptide (cAMP) resistance pathway exhibited the highest $\mathrm{pN} / \mathrm{pS}$ value in a single BACL (BACL13). Antimicrobial peptides (AMPs) play important roles in host defense against microbial infections by weakening the membranes of the microbes, subsequently killing them. AMPs belong to a universal set of defense molecules synthesized across the domains of life [65] and are known to be produced by for example molluscs, crustaceans, ciliates, phytoplankton and bacteria in the marine environment [6670]. Biosynthesis of streptomycin, a well-known antibiotic, which is coupled to inositol phosphate metabolism as part of the molecule is synthesized via myo-inositol. Both of these pathways displayed among the highest $\mathrm{pN} / \mathrm{pS}$ ratios across BACLs. Interestingly Schloissnig et al. [23] showed elevated $\mathrm{pN} / \mathrm{pS}$ ratios for antimicrobial resistance genes in the human gut microbiome. Our findings of elevated evolution in both synthesis and defense genes for antimicrobials suggest that adaptation related to chemical warfare is of central importance also for aquatic bacterioplankton, and raises an unexpected parallel to the human gut ecosystem.

The gene-wise $F_{\mathrm{ST}}$ analysis revealed a small number of genes in most BACLs displaying higher genetic differentiation between the salinity extremes than expected by chance, given the genomes' background levels of genetic differentiation, i.e., the genes were enriched in loci displaying strong genetic differentiation between the samples with lowest and highest salinity. This indicates convergent evolution in multiple strains occupying one or both of the locations, either by the same mutations occurring independently in multiple strains, or by homologous recombination of a genomic segment between the strains, followed by selection. The fact that the polymorphisms of many of the loci displaying high differentiation in these genes were synonymous (i.e., did not cause a change in amino acid), argues for the homologous recombination scenario. Moreover, in several cases, multiple genes adjacent on the genome displayed significant $F_{\mathrm{ST}}$ values, congruent with the recombination scenario. This may in part be attributed to our approach for identifying genes under selection, which is likely to miss cases where the allele frequency of just a single (or very few) sites in a gene has been altered by selection. Among the pathways enriched in highly differentiated genes we find ABC transporters (map02010). This may reflect genetic adaptations to differences in concentrations in inorganic and organic nutrients across the Baltic Sea salinity gradient. One of the ABC transporters was glycine betaine/proline transport system permease protein (in BACL262; Fig. 7). Glycine betaine is a widely used compatible solute (osmoprotectant) in bacteria and is imported or synthesized in response to hyperosmotic stress [71]. A previous metagenomic study found genes for this transporter to be differentially abundant across the Baltic Sea [8]. Another enriched pathway was nitrogen metabolism (map00910). A closer look at this pathway showed that the significant genes are mainly related to glutamine and glutamate synthesis (Supplementary Fig. 4). Glutamine and glutamate both act as osmoprotectants in several bacteria including marine species [72-75] and the differing allele frequencies across the salinity regimes in the genes synthesizing them may reflect adaptations related to underlying enzyme kinetics.

\section{Conclusions}

Facilitated by our recently developed program POGENOM, we show that populations of multiple bacterioplankton clades are genomically structured, even within the same ecosystem. Genomic differentiation within species correlated with environmental variables such as salinity, temperature and nutrient levels across spatial dimensions when accounted for geographic distance. This emphasizes the role of isolation by adaptation rather than isolation by distance as a driving force for speciation of aquatic prokaryotes. Population genomics analysis based on metagenomics data will undoubtedly lead to a deeper understanding of the ecology and evolution of important bacterioplankton species, which is of central importance when learning about how species adapt to new environmental conditions and what their adaptive potential is in the face of Global Change. 


\section{Methods}

\section{POGENOM software}

POGENOM takes as minimal input a file of the variant call format $(\mathrm{VCF})$. This is generated by mapping one or several metagenome samples against a reference genome with a read aligner such as Bowtie2 [76], BWA [77] or MOSAIK [78] and calling variants using a variant caller such as GATK [79] or Freebayes [80]. POGENOM calculates the nucleotide diversity $(\pi)$ within each sample. If multiple samples have been mapped, the fixation index $\left(F_{\mathrm{ST}}\right)$ is calculated for all pairs of samples. If, in addition to the VCF file, an annotation file of the General Feature Format (GFF) is provided, gene-wise $\pi$ and $F_{\mathrm{ST}}$ will be calculated. If, further, the genome sequence is provided in the GFF file or in a separate FASTA file, amino acid frequencies will be calculated for each codon position in each gene and sample, and gene-wise $\pi$ and $F_{\text {ST }}$ will be calculated also at the amino acid level. Now also non-synonymous to synonymous polymorphism rates $(\mathrm{pN} / \mathrm{pS})$ will be calculated for each gene and sample. Optionally, permuted gene-wise $F_{\mathrm{ST}}$ values can be calculated. POGENOM has several optional parameters, such as minimum read depth for a locus to be included for a sample, minimum number of samples with minimum read depth for a locus to be included at all, subsampling to a given read depth, splitting of haplotypes into individual SNVs in case haplotype variant calling was applied, etc. A complete description on how the different parameters are calculated can be found in the Supplementary Information. POGENOM was implemented in Perl. Source code and documentation, and a pipeline for automatic generation of input data (Input_POGENOM), are available at https://github.com/EnvGen/POGENOM.

\section{MAG and shotgun sequencing data}

In total 66 (10 pelagic, 34 coastal, and 22 time series) metagenomic samples, quality filtered as described before [37], were used for population genomic assessments of 22 MAGs. The MAGs were selected based on being prevalent in these samples based on data from Alneberg et al. [37]. Each MAG represents one unique species-level cluster (BAltic Sea CLuster; BACL) and no pair of MAGs in this set have $>80 \%$ average nucleotide identity (ANI). MAGs were taxonomically annotated using GTDB-tk [81] v.0.3.2 using v.89 of the GTDB [82]. Gene calling was conducted with Prokka [83]. The shotgun data used for the population genomic assessments are derived from two cruises: Pelagic Transect 2014 [38] and Coastal Transect 2015 [37], as well as from two years of time-series data from the Linnaeus Microbial Observatory (LMO) station [37]. Sampling, DNA extraction and sequencing procedures have been described earlier [37, 38], but very briefly, surface water was filtered through 0.2 um filters, either directly (transect samples), or after pre-filtration through 3.0 um filter (time-series samples), DNA was extracted from filters and shotgun sequenced on a HiSeq (Illumina) with on average 48 million read-pairs per sample.

\section{Variant calling}

The Input_POGENOM pipeline was used for automatic generation of input files for POGENOM, i.e., VCF files. Briefly (more information provided in the online documentation), Input_POGENOM is a Snakemake [84] pipeline that uses Bowtie2 [76] for read mapping to the reference genome and Freebayes [80] for variant calling. Bowtie2 v.2.3.4.3 was used and the 'bowtie2_params' of Input_POGENOM was set to "-ignore-quals -mp 1,1-np 1 -rdg 0,1-rfg 0,1 -score-min L,0,-0.05”, corresponding to a 95\% identity threshold between read and genome. The parameters 'min_coverage' were set to 20 and 'min_breadth' to 40 , i.e., only samples where the genome displayed $\geq 20 \mathrm{X}$ median coverage depth and $\geq 40 \%$ coverage breadth (fraction of genome covered by at least 1 read) were included for the genome. After mapping, the read-mapping (BAM) files are downsampled to the same coverage (to 'min_coverage') using samtools (v.1.9; [85]). Freebayes v.1.3.1 was used for the variant calling, which is run once per genome, after combining the BAM files from the approved samples into a multi-sample BAM file. The 'freebayes_parameters' was set to "-C 4 -p 1 -pooledcontinuous -read-max-mismatch-fraction 0.05 -min-alternate-fraction $0.01-\mathrm{q} 15$ ", meaning that a SNV was called only when the variant allele was supported by $\geq 4$ reads and with an allele frequency of $\geq 1 \%$. Input_POGENOM was further run in 'prefilt' mode, meaning that it first estimates the coverage of a genome in a sample by only mapping a subset of the reads, in order to fastly eliminate samples unlikely to reach sufficient coverage.

\section{POGENOM runs}

POGENOM v.0.8.2 was run with the parameter settings --min_count 10, --subsample 10, and --min_found 1 on the VCF file of all approved samples for each MAG. In other words, it included for a sample only those loci with allele counts $\geq 10$ (i.e., with $\geq 10$ overlapping reads), and for loci with counts $>10$, it downsampled to counts $=10$. And overall, it included only those loci fulfilling the --min_count conditions for at least one sample. Although we used --min_found 1 here, it may be preferable to set it to the number of samples when for example comparing $\pi$ between samples for the same genome. For comparing actual and permuted gene-wise $F_{\mathrm{ST}}$ values, POGENOM was run on 
only the pair of samples with extreme salinities for each MAG by specifying these samples using the --sample_file parameter, otherwise using the same parameter setting as above except also --fst_perm 10000, meaning that 10,000 permuted $F_{\mathrm{ST}}$ values were computed for each gene.

\section{Environmental association analysis}

Nucleotide diversity was compared against salinity across the Baltic Sea using linear and quadratic regression models. The best model for each MAG was chosen based on AIC values for linear vs. non-linear models. Nucleotide diversity was also studied over time in the LMO data set using Spearman's rank correlation. For the above analyses, and for the data presented in Table 1, we used normalized genome-wide $\pi$, calculated as described in the Supplementary Information. Relating to population structure we conducted environmental association analyses using a global dbRDA (distance-based redundancy analysis) followed by a conditioned analysis. This allowed us to disentangle the relative contribution of different independent variables in driving seascape genomic structure. The global dbRDA was conducted using all environmental variables (salinity, temperature, ammonia, nitrate, phosphate, silicate, chlorophyll a and dissolved organic carbon [and time for LMO samples]). $F_{\mathrm{ST}}$ matrices were subjected to an unconstrained Principal Coordinates Analysis (PCoA) and the PCoA-axes were used as dependent input in the dbRDA. Regression coefficients in the dbRDA are reported as adjusted values of multiple determination $\left(R^{2}\right.$-adj.). Statistical significance of the global dbRDA was evaluated using the permutefunction from vegan and by performing an Anova (by "term", 999 permutations) on the dbRDA result to assess the statistical significance of each variable. The conditioned analysis was only conducted in case the global dbRDA showed statistically significant explanatory power $(p<0.05)$ to avoid Type I error and overestimation of the explained variance [86]. Prior to the conditioned dbRDA we performed a forward selection procedure where variables are added to the model consecutively. The selection stops when adding a variable no longer improves the overall model (threshold, $p<0.05$ ). Statistical significance of conditioned individual fractions (i.e., marginal effects) was evaluated by an Anova (by "margin"; 999 permutations). Time was transformed to PCNM-variables (Principal coordinates of neighbor matrices) by first conducting a PCoA on the matrix for time differences. All eigenvectors with positive values were included in the following RDA analysis where the $F_{\mathrm{ST}}$ matrices of respective MAGs were used as response data. All PCNM variables displaying significant correlation with population structure over time were included side by side with environmental variables in the global dbRDA. Likewise, geographic distance (shortest waterway distance) was transformed to PCNM-variables and used as explanatory variables in the dbRDA.

\section{KEGG pathway analysis}

The genomes were functionally annotated using online eggNOG-mapper [87] which assigned the genes to KEGG pathways, KEGG modules, KEGG orthologs, eggNOGs, and eggNOG functional categories. For the gene-wise pN/ $\mathrm{pS}$ and $F_{\mathrm{ST}}$ analyses, only KEGG pathways that we judged relevant for microbial genomes were included; the pathways belonging to categories $1.1-1.12,2.1-2.4,3.1,4.4-4.5$, and 6.11 (https://www.genome.jp/kegg/pathway.html\#genetic). For the $\mathrm{pN} / \mathrm{pS}$ analysis, only pathways that resulted in $\mathrm{pN} /$ $\mathrm{pS}$ values for $>90 \%$ of the BACLs were included. For the KEGG pathway enrichment analyses, each pathway present in the BACL was checked for overrepresentation of significant genes using Fisher's exact test. The $p$ values from these tests were subsequently adjusted for multiple testing using False Discovery Rate. For genes assigned to multiple pathways, all of the assignments were used. The eggNOG functional category enrichment analyses were done in the same way. The KEGG pathway map of Supplementary Fig. 4 was generated using the KEGG database online resource (https://www.genome.jp/kegg/).

\section{Permutation analysis of gene-wise $F_{\mathrm{ST}}$ values}

POGENOM calculates permuted gene-wise $F_{\mathrm{ST}}$ values for a pair of samples by shuffling all variant loci for the genome so that each gene will get a new set of loci (with their associated allele frequencies) while having the same number of variant loci as in the original data set. Subsequently, gene-wise $F_{\mathrm{ST}}$ values are calculated based on the shuffled data. This procedure is repeated many times and $p$ values can be calculated by comparing the actual $F_{\mathrm{ST}}$ value with the distribution of permuted $F_{\mathrm{ST}}$ values for each gene; here we defined the $p$ value as $\left(1+\right.$ the number of permuted $F_{\mathrm{ST}}$ values $\geq$ the actual $F_{\mathrm{ST}}$ value)/(the number of permutations) and we performed 10,000 permutations.

\section{Data availability}

The MAG sequences as well as the preprocessed sequencing reads from the LMO Time Series 2013-2014 and Coastal Transect 2015 samples were published before (Alneberg, 2020) and are available at ENA hosted by EMBL-EBI under the study accession number PRJEB34883. The preprocessed sequencing reads from the Transect 2014 samples were also published elsewhere (Alneberg, 2018) and are available at ENA under the study accession number PRJEB22997. Source code and documentation for POGENOM are available at https://github.com/EnvGen/POGENOM. 
Acknowledgements The study was supported by KTH SciLifeLab SFO funding. Sampling and DNA sequencing was financed by the BONUS Blueprint project supported by BONUS (Art 185), funded jointly by the EU and the Swedish Research Council FORMAS and by the Swedish Research Council VR (621-2011-5689). We are grateful to Matthias Labrenz and Christin Bennke at IOW for early access to the Transect sample metagenomes. Computations were performed on resources provided by the Swedish National Infrastructure for Computing (SNIC) through the Uppsala Multidisciplinary Center for Advanced Computational Science (UPPMAX). We are grateful to Verena Kutschera at the National Bioinformatics Infrastructure Sweden (NBIS) for valuable input on the population genomics analysis.

\section{Compliance with ethical standards}

Conflict of interest The authors declare no competing interests.

Publisher's note Springer Nature remains neutral with regard to jurisdictional claims in published maps and institutional affiliations.

Open Access This article is licensed under a Creative Commons Attribution 4.0 International License, which permits use, sharing, adaptation, distribution and reproduction in any medium or format, as long as you give appropriate credit to the original author(s) and the source, provide a link to the Creative Commons license, and indicate if changes were made. The images or other third party material in this article are included in the article's Creative Commons license, unless indicated otherwise in a credit line to the material. If material is not included in the article's Creative Commons license and your intended use is not permitted by statutory regulation or exceeds the permitted use, you will need to obtain permission directly from the copyright holder. To view a copy of this license, visit http://creativecommons. org/licenses/by/4.0/.

\section{References}

1. Azam F, Malfatti F. Microbial structuring of marine ecosystems. Nat Rev Microbiol. 2007;5:782-91.

2. Falkowski PG, Fenchel T, Delong EF. The microbial engines that drive Earth's biogeochemical cycles. Science. 2008;320:1034-39.

3. Sunagawa S, Coelho LP, Chaffron S, Kultima JR, Labadie K, Salazar G, et al. Structure and function of the global ocean microbiome. Science. 2015;348:1261359.

4. Giovannoni SJ, Stingl U. Molecular diversity and ecology of microbial plankton. Nature. 2005;437:343-8.

5. DeLong EF, Preston CM, Mincer T, Rich V, Hallam SJ, Frigaard $\mathrm{N}-\mathrm{U}$, et al. Community genomics among stratified microbial assemblages in the ocean's interior. Science. 2006;311:496-503.

6. Field KG, Gordon D, Wright T, Rappé M, Urback E, Vergin K, et al. Diversity and depth-specific distribution of SAR11 cluster rRNA genes from marine planktonic bacteria. Appl Environ Microbiol. 1997;63:63-70.

7. Morris RM, Rappé MS, Connon SA, Vergin KL, Siebold WA, Carlson CA, et al. SAR11 clade dominates ocean surface bacterioplankton communities. Nature. 2002;420:806-10.

8. Dupont CL, Larsson J, Yooseph S, Ininbergs K, Goll J, AsplundSamuelsson J, et al. Functional tradeoffs underpin salinity-driven divergence in microbial community composition. PLoS ONE. 2014;9:e89549.

9. Jaspers E, Overmann J. Ecological significance of microdiversity: identical 16S rRNA gene sequences can be found in bacteria with highly divergent genomes and ecophysiologies. Appl Environ Microbiol. 2004;70:4831-39.
10. Konstantinidis KT, DeLong EF. Genomic patterns of recombination, clonal divergence and environment in marine microbial populations. ISME J. 2008;2:1052-65.

11. Nayfach S, Rodriguez-Mueller B, Garud N, Pollard KS. An integrated metagenomics pipeline for strain profiling reveals novel patterns of bacterial transmission and biogeography. Genome Res. 2016;26:1612-25.

12. Hunt DE, David LA, Gevers D, Preheim SP, Alm EJ, Polz MF. Resource partitioning and sympatric differentiation among closely related bacterioplankton. Science. 2008;320:1081-5.

13. Johnson ZI, Zinser ER, Coe A, McNulty NP, Woodward EMS, Chisholm SW. Niche partitioning among Prochlorococcus ecotypes along ocean-scale environmental gradients. Science. 2006;311:1737-40.

14. Brown MV, Lauro FM, DeMaere MZ, Muir L, Wilkins D, Thomas T, et al. Global biogeography of SAR11 marine bacteria. Mol Syst Biol. 2012;8:595.

15. Giovannoni SJ, Tripp HJ, Givan S, Podar M, Vergin KL, Baptista $\mathrm{D}$, et al. Genome streamlining in a cosmopolitan oceanic bacterium. Science. 2005;309:1242-45.

16. Carlson CA, Morris R, Parsons R, Treusch AH, Giovannoni SJ, Vergin K. Seasonal dynamics of SAR11 populations in the euphotic and mesopelagic zones of the northwestern Sargasso Sea. ISME J. 2009;3:283-95.

17. Moore LR, Rocap G, Chisholm SW. Physiology and molecular phylogeny of coexisting Prochlorococcus ecotypes. Nature. 1998;393:464-7.

18. Rodríguez-Valera F. Approaches to prokaryotic biodiversity: a population genetics perspective. Environ Microbiol. $2002 ; 4: 628-33$.

19. Eloe-Fadrosh EA, Ivanova NN, Woyke T, Kyrpides NC. Metagenomics uncovers gaps in amplicon-based detection of microbial diversity. Nat Microbiol. 2016;1:15032.

20. O'Brien JD, Didelot X, Iqbal Z, Amenga-Etego L, Ahiska B, Falush D. A Bayesian approach to inferring the phylogenetic structure of communities from metagenomic data. Genetics. 2014;197:925-37.

21. Luo C, Knight R, Siljander H, Knip M, Xavier RJ, Gevers D. ConStrains identifies microbial strains in metagenomic datasets. Nat Biotechnol. 2015;33:1045-52.

22. Quince C, Delmont TO, Raguideau S, Alneberg J, Darling AE, Collins G, et al. DESMAN: a new tool for de novo extraction of strains from metagenomes. Genome Biol. 2017;18:181.

23. Schloissnig S, Arumugam M, Sunagawa S, Mitreva M, Tap J, Zhu A, et al. Genomic variation landscape of the human gut microbiome. Nature. 2013;493:45-50.

24. Delmont TO, Kiefl E, Kilinc O, Esen OC, Uysal I, Rappé MS, et al. Single-amino acid variants reveal evolutionary processes that shape the biogeography of a global SAR11 subclade. eLife. 2019;8:e46497.

25. Costea PI, Munch R, Coelho LP, Paoli L, Sunagawa S, Bork P. metaSNV: A tool for metagenomic strain level analysis. PLoS ONE. 2017;12:e0182392.

26. Olm MR, Crits-Christoph A, Bouma-Gregson K, Firek BA, Morowitz MJ, Banfield JF inStrain profiles population microdiversity from metagenomic data and sensitively detects shared microbial strains. Nat Biotechnol. 2021; https://doi.org/10.1038/ s41587-020-00797-0

27. Gabrielsen TM, Brochmann C, Rueness J. The Baltic Sea as a model system for studying postglacial colonization and ecological differentiation, exemplified by the red alga Ceramium tenuicorne. Mol Ecol. 2002;11:2083-95.

28. Johannesson K, André C. Invited review: Life on the margin: genetic isolation and diversity loss in a peripheral marine ecosystem, the Baltic Sea. Mol Ecol. 2006;15:2013-29. 
29. Ojaveer H, Jaanus A, Mackenzie BR, Martin G, Olenin S, Radziejewska T, et al. Status of biodiversity in the Baltic Sea. PLoS ONE. 2010;5:e12467.

30. Bergstrom L, Tatarenkov A, Johannesson K, Jonsson RB, Kautsky L. Genetic and morphological identification of Fucus radicans sp.nov. (Fucales, Phaeophyceae) in the brackish Baltic Sea. J Phycol. 2005;41:1025-38.

31. Jørgensen HBH, Pertoldi C, Hansen MM, Ruzzante DE, Loeschcke V. Genetic and environmental correlates of morphological variation in a marine fish: the case of Baltic Sea herring (Clupea harengus). Can J Fish Aquat Sci. 2008;65:389-400.

32. Martinez Barrio A, Lamichhaney S, Fan G, Rafati N, Pettersson $\mathrm{M}$, Zhang $\mathrm{H}$, et al. The genetic basis for ecological adaptation of the Atlantic herring revealed by genome sequencing. eLife. 2016;5:e12081.

33. Sjöqvist C, Godhe A, Jonsson PR, Sundqvist L, Kremp A. Local adaptation and oceanographic connectivity patterns explain genetic differentiation of a marine diatom across the North SeaBaltic Sea salinity gradient. Mol Ecol. 2015;24:2871-85.

34. Herlemann DPR, Labrenz M, Jürgens K, Bertilsson S, Waniek JJ, Andersson AF. Transitions in bacterial communities along the $2000 \mathrm{~km}$ salinity gradient of the Baltic Sea. ISME J. 2011;5:1571-9.

35. Herlemann DPR, Lundin D, Andersson AF, Labrenz M, Jürgens $\mathrm{K}$. Phylogenetic signals of salinity and season in bacterial community composition across the salinity gradient of the Baltic Sea. Front Microbiol. 2016;7:1883.

36. Hugerth LW, Larsson J, Alneberg J, Lindh MV, Legrand C, Pinhassi $\mathrm{J}$, et al. Metagenome-assembled genomes uncover a global brackish microbiome. Genome Biol. 2015;16:279.

37. Alneberg J, Bennke C, Beier S, Bunse C, Quince C, Ininbergs K, et al. Ecosystem-wide metagenomic binning enables prediction of ecological niches from genomes. Commun Biol. 2020;3:119.

38. Alneberg J, Karlsson CMG, Divne A-M, Bergin C, Homa F, Lindh MV, et al. Genomes from uncultivated prokaryotes: a comparison of metagenome-assembled and single-amplified genomes. Microbiome. 2018;6:173.

39. Lira-Noriega A, Manthey JD. Relationship of genetic diversity and niche centrality: a survey and analysis. Evolution. 2014;68:1082-93.

40. Alneberg J, Bjarnason BS, de Bruijn I, Schirmer M, Quick J, Ijaz $\mathrm{UZ}$, et al. Binning metagenomic contigs by coverage and composition. Nat Methods. 2014;11:1144-6.

41. Martincorena I, Seshasayee ASN, Luscombe NM. Evidence of non-random mutation rates suggests an evolutionary risk management strategy. Nature. 2012;485:95-98.

42. Bohlin J, Brynildsrud OB, Sekse C, Snipen L. An evolutionary analysis of genome expansion and pathogenicity in Escherichia coli. BMC Genomics. 2014;15:882.

43. Kanehisa M, Goto S. KEGG: kyoto encyclopedia of genes and genomes. Nucleic Acids Res. 2000;28:27-30.

44. Wright S. Evolution in Mendelian populations. Genetics. 1931;16:97-159.

45. Nei M. Analysis of gene diversity in subdivided populations. Proc Natl Acad Sci USA 1973;70:3321-3.

46. Hu YOO, Karlson B, Charvet S, Andersson AF. Diversity of picoto mesoplankton along the $2000 \mathrm{~km}$ salinity gradient of the Baltic Sea. Front Microbiol. 2016;7:679.

47. Andersson AF, Riemann L, Bertilsson S. Pyrosequencing reveals contrasting seasonal dynamics of taxa within Baltic Sea bacterioplankton communities. ISME J. 2010;4:171-81.

48. Lindh MV, Sjöstedt J, Andersson AF, Baltar F, Hugerth LW, Lundin D, et al. Disentangling seasonal bacterioplankton population dynamics by high-frequency sampling. Environ Microbiol. 2015;17:2459-76.
49. Berg PR, Jentoft S, Star B, Ring KH, Knutsen H, Lien S, et al. Adaptation to low salinity promotes genomic divergence in Atlantic cod (Gadus morhua L.). Genome Biol Evol. 2015;7:1644-63.

50. Feder JL, Egan SP, Nosil P. The genomics of speciation-withgene-flow. Trends Genet. 2012;28:342-50.

51. Gevers D, Cohan FM, Lawrence JG, Spratt BG, Coenye T, Feil EJ, et al. Opinion: Re-evaluating prokaryotic species. Nat Rev Microbiol. 2005;3:733-9.

52. Coleman ML, Sullivan MB, Martiny AC, Steglich C, Barry K, Delong EF, et al. Genomic islands and the ecology and evolution of Prochlorococcus. Science. 2006;311:1768-70.

53. Kettler GC, Martiny AC, Huang K, Zucker J, Coleman ML, Rodrigue $\mathrm{S}$, et al. Patterns and implications of gene gain and loss in the evolution of Prochlorococcus. PLoS Genet. 2007;3:e231.

54. Fernández-Gómez B, Fernàndez-Guerra A, Casamayor EO, González JM, Pedrós-Alió C, Acinas SG. Patterns and architecture of genomic islands in marine bacteria. BMC Genomics. 2012;13:347.

55. Qin Q-L, Xie B-B, Yu Y, Shu Y-L, Rong J-C, Zhang Y-J, et al. Comparative genomics of the marine bacterial genus Glaciecola reveals the high degree of genomic diversity and genomic characteristic for cold adaptation. Environ Microbiol. 2014;16:1642-53.

56. Hahn MW, Lünsdorf H, Wu Q, Schauer M, Höfle MG, Boenigk J, et al. Isolation of novel ultramicrobacteria classified as actinobacteria from five freshwater habitats in Europe and Asia. Appl Environ Microbiol. 2003;69:1442-51.

57. Glöckner FO, Zaichikov E, Belkova N, Denissova L, Pernthaler J, Pernthaler A, et al. Comparative 16S rRNA analysis of lake bacterioplankton reveals globally distributed phylogenetic clusters including an abundant group of Actinobacteria. Appl Environ Microbiol. 2000;66:5053-65.

58. Neuenschwander SM, Ghai R, Pernthaler J, Salcher MM Microdiversification in genome-streamlined ubiquitous freshwater Actinobacteria. ISME J. 2018;12:185-98.

59. Li WKW. Annual average abundance of heterotrophic bacteria and Synechococcus in surface ocean waters. Limnol Oceanogr. 1998;43:1746-53

60. Fuhrman JA, Steele JA. Community structure of marine bacterioplankton: patterns, networks, and relationships to function. Aquat Micro Ecol. 2008;53:69-81.

61. Fuhrman JA, Steele JA, Hewson I, Schwalbach MS, Brown MV, Green JL, et al. A latitudinal diversity gradient in planktonic marine bacteria. Proc Natl Acad Sci USA 2008;105:7774-8.

62. Kawecki TJ. Adaptation to marginal habitats. Annu Rev Ecol Evol Syst. 2008;39:321-42.

63. Oren A. Bioenergetic aspects of halophilism. Microbiol Mol Biol Rev. 1999;63:334-48.

64. Cabello-Yeves PJ, Rodriguez-Valera F. Marine-freshwater prokaryotic transitions require extensive changes in the predicted proteome. Microbiome. 2019;7:117.

65. Yeaman MR, Yount NY. Unifying themes in host defence effector polypeptides. Nat Rev Microbiol. 2007;5:727-40.

66. Guzmán F, Wong G, Román T, Cárdenas C, Alvárez C, Schmitt $\mathrm{P}$, et al. Identification of antimicrobial peptides from the microalgae Tetraselmis suecica (Kylin) Butcher and bactericidal activity improvement. Mar Drugs. 2019;17:453.

67. Sperstad SV, Haug T, Blencke H-M, Styrvold OB, Li C, Stensvåg K. Antimicrobial peptides from marine invertebrates: challenges and perspectives in marine antimicrobial peptide discovery. Biotechnol Adv. 2011;29:519-30.

68. Mitta G, Hubert F, Dyrynda EA, Boudry P, Roch P, Mytilin B. and MGD2, two antimicrobial peptides of marine mussels: gene structure and expression analysis. Dev Comp Immunol. 2000;24:381-93. 
69. Smith VJ, Fernandes JMO, Kemp GD, Hauton C. Crustins: enigmatic WAP domain-containing antibacterial proteins from crustaceans. Dev Comp Immunol. 2008;32:758-72.

70. Tareq FS, Lee MA, Lee H-S, Lee J-S, Lee Y-J, Shin HJ, et al. antimicrobial linear lipopeptides from a marine Bacillus subtilis. Mar Drugs. 2014;12:871-85.

71. Oren A. Formation and breakdown of glycine betaine and trimethylamine in hypersaline environments. Antonie Van Leeuwenhoek. 1990;58:291-8.

72. Stanley SO, Brown CM. Inorganic nitrogen metabolism in marine bacteria: the intracellular free amino acid pools of a marine pseudomonad. Mar Biol. 1976;38:101-9.

73. Makemson JC, Hastings JW. Glutamate functions in osmoregulation in a marine bacterium. Appl Environ Microbiol. 1979;38:178-80.

74. Robertson DE, Roberts MF, Belay N, Stetter KO, Boone DR. Occurrence of beta-glutamate, a novel osmolyte, in marine methanogenic bacteria. Appl Environ Microbiol. 1990;56:1504-8.

75. Goude R, Renaud S, Bonnassie S, Bernard T, Blanco C. Glutamine, glutamate, and $\alpha$-glucosylglycerate are the major osmotic solutes accumulated by Erwinia chrysanthemi strain 3937. Appl Environ Microbiol. 2004;70:6535-41.

76. Langmead B, Salzberg SL. Fast gapped-read alignment with Bowtie 2. Nat Methods. 2012;9:357-9.

77. Li H, Durbin R. Fast and accurate short read alignment with Burrows-Wheeler transform. Bioinformatics. 2009;25:1754-60.

78. Lee W-P, Stromberg MP, Ward A, Stewart C, Garrison EP, Marth GT. MOSAIK: a hash-based algorithm for accurate nextgeneration sequencing short-read mapping. PLoS ONE. 2014;9: e90581.
79. Van der Auwera GA, Carneiro MO, Hartl C, Poplin R, Del Angel G, Levy-Moonshine A, et al. From FastQ data to high confidence variant calls: the Genome Analysis Toolkit best practices pipeline. Curr Protoc Bioinforma. 2013;43:11.10.1-11.10.33.

80. Garrison E, Marth G. Haplotype-based variant detection from short-read sequencing. 2012; arXiv:1207.3907 [q-bioGN].

81. Chaumeil PA, Mussig AJ, Hugenholtz P, Parks DH. GTDB-Tk: a toolkit to classify genomes with the Genome Taxonomy Database. Bioinformatics. 2019;15:1925-7.

82. Parks DH, Chuvochina M, Waite DW, Rinke C, Skarshewski A, Chaumeil P-A, et al. A standardized bacterial taxonomy based on genome phylogeny substantially revises the tree of life. Nat Biotechnol. 2018;36:996-1004.

83. Seemann T. Prokka: rapid prokaryotic genome annotation. Bioinformatics. 2014;30:2068-9.

84. Köster J, Rahmann S. Snakemake - a scalable bioinformatics workflow engine. Bioinformatics. 2012;28:2520-2.

85. Li H, Handsaker B, Wysoker A, Fennell T, Ruan J, Homer N, et al. The sequence alignment/map format and SAMtools. Bioinformatics. 2009;25:2078-9.

86. Blanchet FG, Legendre P, Borcard D. Forward selection of explanatory variables. Ecology. 2008;89:2623-32.

87. Huerta-Cepas J, Forslund K, Coelho LP, Szklarczyk D, Jensen LJ, von Mering $\mathrm{C}$, et al. Fast genome-wide functional annotation through orthology assignment by eggNOG-Mapper. Mol Biol Evol. 2017;34:2115-22.

88. Telesh IV, Schubert H, Skarlato SO. Revisiting Remane's concept: evidence for high plankton diversity and a protistan species maximum in the horohalinicum of the Baltic Sea. Mar Ecol Prog Ser. 2011;421:1-11. 